\title{
Sublingual Immunotherapy in Asthma Does Not Influence LyMPHOCYTE SENSITIVITY TO FAS STIMULATION
}

\author{
O. Ciepiela ${ }^{1}$, A. Zawadzka-Krajewska², I. Kotula1 ${ }^{1}$ M. Wasik¹, U. Demkow ${ }^{1}$ \\ ${ }^{1}$ Department of Laboratory Diagnostics and Clinical Immunology of Developmental Age, Warsaw Medical University, Warsaw, Poland; \\ ${ }^{2}$ Department of Pediatric Pneumology and Allergology, Warsaw Medical University, Warsaw, Poland
}

\begin{abstract}
Background: The resistance of $\mathrm{T}$ lymphocytes to Fasmediated apoptosis is an important feature of atopic asthma. The only effective causative treatment of atopic diseases is immunotherapy. Clinical efficacy of sublingual immunotherapy (SLIT) has been already proven, but there is still limited number of studies on its influence on lymphocytes function.

Objectives: The aim of the study was to evaluate whether SLIT could restore the sensitivity of asthmatic T cells to undergo Fas-mediated apoptosis.

Material and methods: Peripheral blood was collected from 12 patients aged $8 \pm 2$ years suffering from atopic asthma and undergoing sublingual specific immunotherapy. To evaluate sensitivity to Fas-mediated apoptosis, the blood was transmitted to sterile tubes and mixed with purified monoclonal antibody antiCD95. After incubation, leukocytes were stained with Annexin V, propidium iodide, and monoclonal antibody against CD2 conjugated with phycoerythrincyanin 5.1, and then analyzed with flow cytometry. The procedure was repeated for each patient after 12 months of SLIT.

Results: Stimulation with anti-CD95 of T lymphocytes from patients with atopic asthma before treatment increased the number of early apoptotic cells (from 19.5 $\pm 16.7 \%$ before stimulation to $26.6 \pm 16.7 \%$ Annexin V positive cells after stimulation). After one year of SLIT anti-CD95 still caused an increase of the early apoptotic cells ratio in the lymphocyte population (from $12.4 \pm 7.4 \%$ before stimulation to $24.7 \pm 15.4 \%$ Annexin $\mathrm{V}$ positive $\mathrm{T}$ cells after CD95 stimulation). Although an increasing trend could be observed, differences between the analyzed groups were not statistically significant.

Conclusions: A year of SLIT does not change the sensitivity of $\mathrm{T}$ lymphocytes from peripheral blood of children suffering from atopic asthma to Fas-mediated apoptosis.
\end{abstract}

Key words: atopic asthma, apoptosis, sublingual immunotherapy, Fas

\section{INTRODUCTION}

Asthma is a chronic inflammatory disease of airways. It develops as a result of late phase hypersensitivity to different allergens being driven by a specialized subset of chronically activated $\mathrm{T}$ memory cells sensitized against an array of antigens. Physiologically naive $\mathrm{T}$ helper lymphocytes differentiate mainly to Th1 subpopulation. The minority of the Th0 cells differentiate to Th2 subpopulation under the influence of cytokines released from mast cells and other activated Th2 lymphocytes. In asthma, the balance between both Th lymphocyte subpopulations is shifted toward Th2. Cytokines produced by Th2 lymphocytes cause $\mathrm{IgE}$ overproduction as well as proliferation of eosinophils and basophils in the bone marrow. On the other hand, $\operatorname{IgE}$ causes degranulation of basophils and mast cells, while released mediators contribute to the development of chronic lung inflammation [1].

A sustained imbalance of Th lymphocytes could be a result of improper lymphocytic apoptosis. There are three different mechanisms of programmed cell death. A first one is generated by signals arising within the cell, a second is triggered by death activators' binding to receptors at the cell surface (FasL, TNF- $\alpha$ ), and a third may be triggered by reactive oxygen species. Death of peripheral $\mathrm{T}$ cells requires the action of a death receptor/ligand system, particularly Fas (CD95)and Fas-ligand interaction. Pro-apoptotic signals lead to the recruitment of pro-caspase- 8 to the receptor, forming the death-inducing signaling complex. Once activated, caspase- 8 can initiate apoptosis of a cell [2]. Some data show a selective resistance of activated $\mathrm{T}$ cells to Fas-induced apoptosis in patients with asthma compared with healthy subjects. It could be a potent mechanism of persistent $\mathrm{T}$ cell activation and an impaired ratio of Th cells [3]. The main apoptotic pathway is the system of the surface molecules Fas-Fas ligand expressed after activation of a cell. Modzelewska et al [4] has described the presence of around $20 \%$ of resting $\mathrm{T}$ lymphocytes, CD2 positive, in peripheral blood expressing CD95 on the cell surface.

Atopic asthma could be treated with specific immunotherapy. Administration of increasing doses of allergens might desensitize $T$ cells against specific antigens [5]. Nowadays, sublingual immunotherapy (SLIT) is of an interest of pediatric allergologists. This route of delivery is patient friendly (especially in children), safe, and can be administered at home [5-7]. Clinical efficacy of SLIT has already been proven $[8,9]$. The aim of the present study was to analyze whether SLIT cold restore the sensitivity of T cells in asthma to Fasmediated apoptosis. 


\section{MATERIAL AND METHODS}

\section{Patients}

The experiments were approved by the Ethics Commission of Warsaw Medical University in Warsaw, Poland and the blood was collected with parental approval.

Twelve individuals aged of $8 \pm 2$ years (before immunotherapy) suffering from atopic asthma, confirmed by skin prick test (positive to Dermatophagoides pteronyssinus allergens), shortlisted for specific immunotherapy, served as a studied group. None was treated with antihistamine drugs or oral corticosteroids. $1 \mathrm{ml}$ of blood, taken by venipuncture to vials containing EDTA (Medlab, Poland), was collected. Tests were performed before and after 12 months of specific SLIT. The patients were receiving Staloral 300 (Stallergenes, France) in concentration of $300 \mathrm{IR} / \mathrm{ml}$ according to physician's indications.

\section{ANTI-CD95 STIMULATION}

$200 \mu \mathrm{l}$ of whole blood was transmitted to sterile vials and mixed with $20 \mu \mathrm{l}$ of purified monoclonal antibody anti-CD95 (Beckman Coulter, U.K.) in concentration of $0.2 \mathrm{mg} / \mathrm{ml}$. For the evaluation of spontaneous apoptosis, $200 \mu \mathrm{l}$ of whole blood from the same patient was mixed with $20 \mu \mathrm{l}$ of phosphate buffered saline (PBS). Vials were incubated for $24 \mathrm{~h}$ at $37^{\circ} \mathrm{C}$, $5 \% \mathrm{CO}_{2}$, humidity $95 \%$.

\section{AnNexin V AND PRopidium Iodide LABELING}

The staining followed the instructions of a manufacturer of Annexin V Kit (Becton Dickinson, USA). Leukocytes were washed twice with cold PBS, resuspended in $100 \mu \mathrm{l}$ of Binding Buffer, stained with $5 \mu \mathrm{l}$ of Annexin V and $5 \mu$ of PI, incubated for $15 \mathrm{~min}$ in the dark at room temperature, and resuspended in 400 $\mu \mathrm{l}$ of Binding Buffer.

\section{FLOW CYTOMETRY}

Suspensions were analyzed with a Cytomics FC 500 flow cytometer equipped with argon laser (488 nm)
(Beckman Coulter, U.K.). A three-color analysis of apoptosis within the mononuclear cell population was performed. Fluorescence compensation in the flow cytometer was set to minimize an overlap of the fluorescein isothiocyanate (FITC) phycoeritrine (PE) and PI signals. A total of 20000 events were acquired for each sample. The analysis was based on gating a subpopulation of cells by forward (FS) vs. side scatter (SS). Mononuclear cells were analyzed with the FL2 protocol (CD2-PE) to separate T lymphocytes with a high expression of CD2 antigen. Gated T lymphocytes were further analyzed with the FL1 (annexin V - FITC) and FL3 protocols (PI) to evaluate the presence and percentage of apoptotic cells among the examined cells.

Results were presented as means \pm SD. Statistical analysis was performed by using the Mann-Whitney U test. $\mathrm{P}<0.05$ was considered significant.

\section{RESULTS}

Percentages of early and late apoptotic T lymphocytes were evaluated from the flow cytograms (Fig. 1). Before SLIT, $19.5 \pm 16.7 \%$ of $T$ lymphocytes were Annexin $\mathrm{V}$ positive before Fas stimulation compared with $26.6 \pm 16.7 \%$ positive cells after stimulation (Fig. $2 \mathrm{~A}$ ). After one year of SLIT, $12.4 \pm 7.4 \%$ of $\mathrm{T}$ lymphocytes
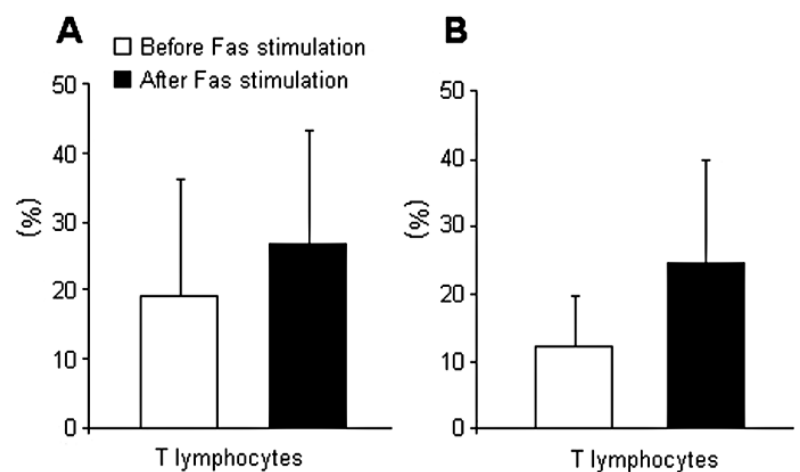

Fig. 2. Percentages of Annexin V positive T lymphocytes before and after Fas stimulation in peripheral blood of children before (Panel A) and after one year (Panel B) of sublingual immunotherapy.
I

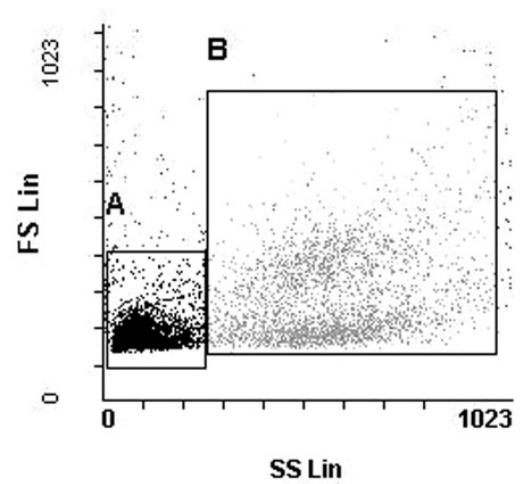

II

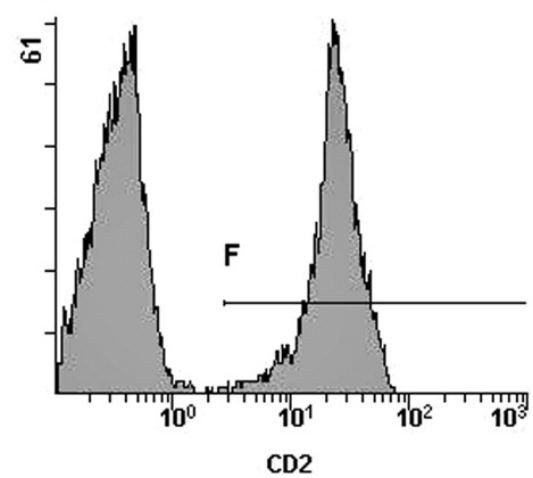

III

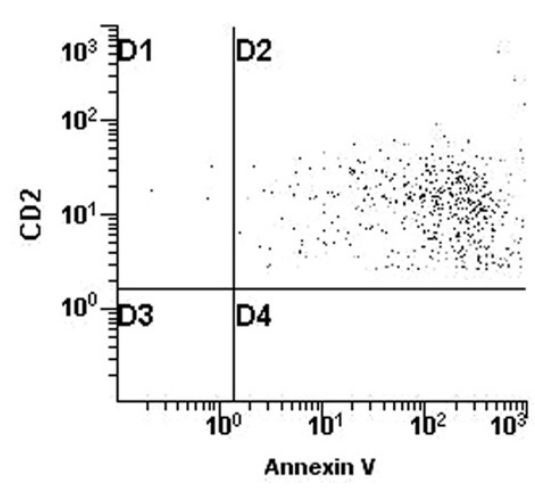

Fig. 1. Examples of flow cytograms presenting T lymphocyte gating and AnnexinV/PI staining within mononuclear cells. I layout of all blood populations in forward scatter/side scatter protocol after Annexin V/propidium iodide staining: region A peripheral blood mononuclear cells, region B - granulocytes; II - gating of CD2 positive T cells (region F); III - evaluation of Annexin $\mathrm{V}$ positive T cells among CD2 positive lymphocytes: region D1 - T lymphocytes without phosphatydylserine expression, D2 - double positive lymphocytes. 


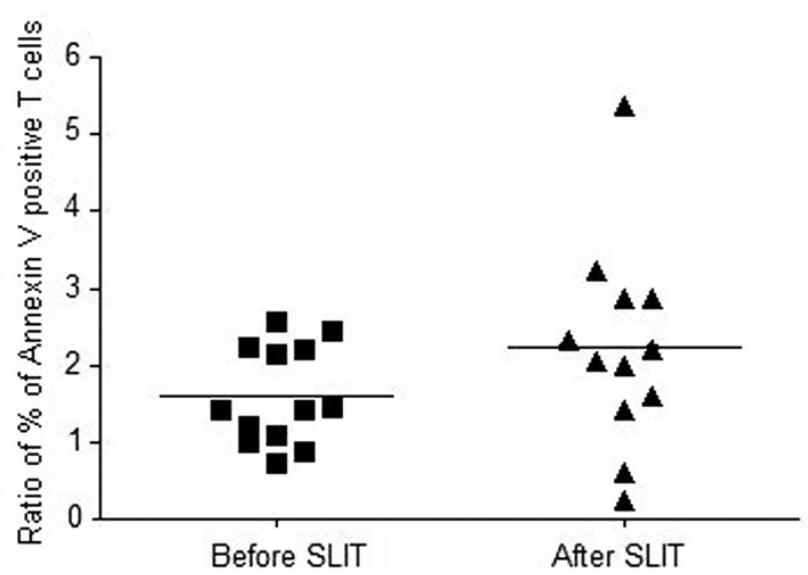

Fig. 3. Comparison of anti-CD95 effect on T lymphocytes before and after one year of sublingual immunotherapy (SLIT).

were Annexin V positive before Fas stimulation compared with $24.7 \pm 15.3 \%$ positive cells after stimulation (Fig. 2B)

The results were also expressed as a ratio of the percentage of Annexin $\mathrm{V}$ positive $\mathrm{T}$ lymphocytes in children with atopic asthma after Fas stimulation and to that before Fas stimulation, i.e., incubation with anti-CD95 monoclonal antibody. Stimulation of $\mathrm{T}$ lymphocytes before SLIT treatment, increased the ratio of the percentages of early apoptotic cells in the lymphocyte population $1.7 \pm 0.7$ times. After one year of SLIT treatment, anti-CD95 caused a further increase in this ratio to $2.2 \pm 1.3$ times; however, this difference was not statistically significant $(\mathrm{P}=0.22)$ (Fig. 3).

\section{DISCUSSION}

Apoptosis plays an essential role in every cellular system. It ensures death of cells with damaged DNA, protects against impaired cell's maturation, and guarantees the balance in the immunological system [10]. Naive helper $\mathrm{T}$ lymphocytes differentiate mainly to Th1 subpopulation in healthy subjects. Th2 lymphocytes stay in a minority. In asthma the balance is shifted toward the Th2. Th0 cells differentiate mainly to Th2 subpopulation $[1,11]$. It is suggested that the imbalance is a result of a disturbed apoptosis process in the T lymphocyte subpopulations [1, 3, 11-14].

It is postulated that $T$ lymphocytes from asthmatic children are resistant to Fas-mediated apoptosis [3, 14]. In the present study, stimulation with anti-CD95 (anti-Fas) monoclonal antibody was performed to assess the sensitivity of asthmatic T cells to Fas stimulation. In both studied groups of children suffering from atopic asthma we observed decreased apoptosis of $\mathrm{T}$ cells. It is in accordance with the results obtained by other groups, showing that Fas-mediated apoptosis of lymphocytes from patients with asthma is impaired $[3,14]$.

To examine the influence of SLIT on the resistance to Fas-mediated apoptosis, the experiments were repeated after one year of immunotherapy. SLIT is an effective treatment in atopic diseases $[8,9]$. Long-term
SLIT improves the patient's quality of life, allows decreasing the intake of antihistamine and oral corticosteroid drugs, and contributes to a decreased number of asthmatic incidences after contact with allergens $[7$, $15,16]$. However, the influence of SLIT on immune cell functions remains unclear. There are few reports describing the impact of SLIT on T cell balance or enzyme release from eosinophils [15, 17-20]. Nevertheless, the effect of SLIT on Fas-mediated apoptosis of lymphocytes has not been examined to-date. Moreover, a majority of authors evaluate the SLIT efficacy in adults. Only do scarce studies include pediatric patients and the results are less optimistic [21]. In the present study, our aim was to assess the SLIT influence on lymphocyte Fas-mediated apoptosis. Bohle et al [17] have reported that high dose sublingual immunotherapy may increase the apoptosis ratio among Th2 lymphocyte subpopulations. In that study, however, the surface CD95 expression was not investigated. Other authors show that $18.0 \pm 6.4 \%$ of $C D 2$ positive T cells express the CD95 antigen on their surface [4]. On the other hand, Zak-Nejmark et al [22] have reported a significantly lower CD95 expression on the resting lymphocytes (as low as 1\%). Those authors have also analyzed the CD95 expression on the cells from sensitized patients after the proper allergen activation. A significant increase has been observed compared with the resting cells (up to $7.5 \pm 2.8 \%$ ), albeit lower than that obtained by us in a previous study $(18.0 \pm 6.4 \%)$ [23]. Since the Fas pathway is regarded as one of the most important triggers of apoptosis, its relation and influence on the programmed death of analyzed cells should not be ignored and further studies are needed to confirm our observations. We have previously shown a significant difference in apoptosis of non-stimulated and Fas-stimulated peripheral blood mononuclear cells from healthy individuals [23]. Similar results have also been obtained by Jayaraman et al [3]. In the present study, Fas stimulation of cells from patients after immunotherapy caused a slight, insignificant increase of lymphocyte apoptosis. Perhaps, future studies performed on larger populations of patients would allow achieving straightforward conclusions. The lack of a strong influence of SLIT on Fas-mediated apoptosis may also result from too short a period of immunotherapy. One year of SLIT, albeit clinically effective, may not be sufficient to obtain substantial inherent changes in the immune regulation [24]. It is postulated to continue sublingual immunotherapy for at least 2-3 years to get satisfactory results $[5,8]$. Thus, the experiments should be repeated after a full course of treatment.

Acknowledgments: This project was co-financed by Ph.D. grant $1 \mathrm{WW} / \mathrm{NK} 1 \mathrm{D} / 09$ of the Medical University of Warsaw and a 2008-2009 scholarship funded by Mazovia Voivodeship.

Conflicts of interest: The authors declared no conflict of interest in relation to this article.

\section{REFERENCES}

1. Hamzaoui A, Hamzaoui K, Salah H, Chabbou A. Lymphocytes apoptosis in patients with acute exacerbation of asthma. Mediators of Inflammation. 1999; 8: 237-43. 
2. Siegel RM, Fleisher TA. The role of Fas and related death receptors in autoimmune and other disease states. J Allergy Clin Immunol 1999; 103: 729-38.

3. Jayaraman S, Castro M, O'Sullivan M, Bragdon MJ, Holtzman MJ. Resistance to Fas-mediated T cell apoptosis in asthma. J Immunol 1999; 162: 1717-22.

4. Modzelewska M, Wasik M. Expression of proteins regulating apoptosis and sensitivity to drugs in bone marrow and peripheral blond cells. Acta Haematol Pol 2004; 35: 243-50 (article in Polish).

5. Cox L. Sublingual immunotherapy in pediatric allergic rhinitis and asthma: efficacy, safety, and practical considerations. Curr Allergy Asthma Rep 2007; 7: 410-20.

6. Rodríguez-Pérez N, Ambriz-Moreno Mde J, Canonica GW, Penagos M. Frequency of acute systemic reactions in patients with allergic rhinitis and asthma treated with sublingual immunotherapy. Ann Allergy Asthma Immunol 2008; 101: 304-10.

7. Passalacqua G, Baena-Cagnani CE, Berardi M, Canonica GW. Oral and sublingual immunotherapy in pediatric patients. Curr Opin Allergy Clin Immunol 2003; 3: 139-45.

8. Passalacqua G, Pasquali M, Ariano R, Lombardi C, Giardini A, Baiardini I, Majani G, Falagiani P, Bruno M, Canonica GW. Randomized double-blind controlled study with sublingual carbamylated allergoid immunotherapy in mild rhinitis due to mites. Allergy 2006; 61: 849-54.

9. Antunez C, Mayorga C, Corzo JL, Jurado A, Torres MJ. Two year follow-up of immunological response in miteallergic children treated with sublingual immunotherapy. Comparison with subcutaneous administration. Pediatr Allergy Immunol 2008; 19: 210-18.

10. Bertho AL, Santiago MA, Coutinho SG. Flow cytometry in the study of cell death. Mem Inst Oswaldo Cruz, Rio de Janeiro 2000; 95: 429-33.

11. Akkoc T, de Koning JA, Ruckert B, Barlan I, Akdis M, Akdis CA. Increased activation-induced cell death of high IFN- $\gamma$ producing Th1 cells as a mechanism of Th2 predominance in atopic diseases. J Allergy Clin Immunol 2008; 121: 652-8.

12. Zhang X, Brunner T, Carter L, Dutton RW, Rogers P, Bradley L, Sato T, Reed JC, Green D, Swain SL. Unequal death in T helper cell (Th1) and Th2 effectors: Th1, but not Th2, effectors undergo rapid Fas/FasL-mediated apoptosis. J Exp Med 1997; 185: 1837-49.

13. Akdis M, Trautmann A, Klunker S, Daigle I, Kucuksezer UC, Deglmann W, Disch R, Blaser K, Akdis CA. T helper (Th) 2 predominance in atopic diseases is due to preferential apoptosis of circulating memory/effector Th1 cells. FASEB J 2003; 17: 1026-35.

14. Varadhachary AS, Peter ME, Perdow SN, Krammer PH, Salgame P. Selective up-regulation of phosphatidylinositol 3'-kinase activity in Th2 cells inhibits caspaze-8 cleavage at the death-inducing complex: a mechanism for Th2 resistance from Fas-mediated apoptosis. J Immunol 1999; 163: 4772-9.

15. Cox LS, Larenas Linnemann D, Nolte H, Weldon D, Finegold I, Nelson HS. Sublingual immunotherapy: a comprehensive review. J Allergy Clin Immunol 2006; 117: 1021-35.
16. Larenas-Linnemann D. Sublingual immunotherapy in children: complete and updated review supporting evidence of effect. Curr Opin Allergy Clin Immunol 2009; 9: 168-76.

17. Bohle B, Kinciyan T, Gerstmayr M, Radakovics A, JahnSchmid B, Ebner C. Sublingual immunotherapy induces IL-10-producing T regulatory cells, allergen specific T-cell tolerance, and immune deviation. J Allergy Clin Immunol 2007; 120: 707- 13.

18. Cosmi L, Santarlasci V, Angeli R, Liotta F, Maggi L, Frosali F, Rossi O, Falagiani P, Riva G, Romagnani S, Annunziato F, Maggi E. Sublingual immunotherapy with Dermatophagoides monomeric allergoid down-regulates allergen-specific immunoglobulin $\mathrm{E}$ and increases both interferon gamma and interleukin-10-production. Clin Exp Allerg 2006; 36: 261-72.

19. Moingeon P, Batard T, Fadel R, Frati F, Sieber J, Van Overtvelt L. Immune mechanisms of allergen-specific sublingual immunotherapy. Allergy 2006; 61: 151-65.

20. Larche M, Akdis CA, Valenta R. Immunological mechanisms of allergen-specific immunotherapy. Nat Rev Immunol 2006; 5: 761-71.

21. Dehlink E, Eiwegger T, Gerstmayr M, Kampl E, Bohle B, Chen K-W, Vrtala S, Urbanek R, Szépfalusi Z. Absence of systemic immunologic changes during dose build-up phase and early maintenance period in effective specific sublingual immunotherapy in children Clin Exp Allergy 2006; 36: 32-9

22. Zak-Nejmark T, Malolepszy J, Nowak IA, Kraus-Filarska M. Specific allergen induces Fas (CD95) and FasL (CD95L) expression on peripheral blood mononuclear cells from allergic subjects. Centr Eur J Immunol 2003; 28: 58-61.

23. Potapinska O, Kotula I, Zawadzka-Krajewska A, Pyrzak B, Gomulka K, Wasik M, Demkow U. Evaluation of lymphocytes sensitivity to Fas stimulation in healthy and asthmatic children. Folia Histochem Cytobiol 2009; 47: 647-51.

24. Rolinck-Werninghaus C, Kopp M, Liebke C, Lange J, Wahn U, Niggemann B. Lack of detectable alterations in immune responses during sublingual immunotherapy in children with seasonal allergic rhinoconjunctivitis to grass pollen. Int Arch Allergy Immunol 2005; 136: 134-41.

Address for correspondence:

Olga Ciepiela

Department of Laboratory Diagnostics and

Clinical Immunology of Developmental Age

Warsaw Medical University

24, Marszalkowska St.

00-576 Warsaw

Poland

E-mail: olga.ciepiela@wum.edu.pl 